\title{
Hubungan Pengetahuan Pasien Hipertensi dengan Clinical Outcome Pasien Hipertensi di Poli Penyakit Dalam RSUP DR. M. Djamil Padang
}

(The relationship between knowledge of hypertensive patients and clinical outcome of the hypertensive patients in Poly Internal RSUP DR M. Djamil Padang)

\author{
Dilla Sastri Mara* Yelly Oktavia Sari, \& Suhatri \\ Fakultas Farmasi Universitas Andalas, Jl. Limau Manis, Kec. Pauh, Kota Padang, Sumatera Barat 25163, Indonesia
}

\begin{abstract}
Hypertension is a common cause in increasing mortality and morbidity in the community. Besides being the silent killer the prevalence of this disease is increasing throughout the world. Prevalence of hypertension in indonesia in 2013 was $25,8 \%$ and increased to $34,1 \%$ in 2018. This study aims to determine the characteristics of hypertensive patients, find out the relationship between sociodemographic characteristics and the level of knowledge of hypertensive patients and knowing the relationship between the level of knowledge of hypertensive patients and clinical outcome. Is a quantitative descriptive study using a cross sectional design performed on hypertensive patients in poly internal medicine RSUP DR. M. Djamil Padang in February to April 2019. The sampling technique was purposive sampling and determining the level of respondents knowledge was know from the score obtained through interviews using a validated questionnaire. Data analysis using chi square statistics. The results of 114 respondents with characteristics of $50 \%$ of male patients and $50 \%$ of female patients were obtained, age group with a age range of $46-55$ years $(31,6 \%)$, high school education $(46,5 \%)$, most work is self-employed $(33,3 \%)$. There was no significant relationship between gender and age of hypertensive patients with level of knowledge and there was significant relationship between education and type of work of hypertensive patients with level of knowledge. From this study it was conclused that there was a significant relationship between the level of knowledge of hypertensive patients and clinical outcome.
\end{abstract}

Keywords: knowledge; hypertensive; clinical outcome; RSUP DR. M Djamil.

ABSTRAK: Hipertensi merupakan penyebab umum dalam peningkatan angka mortalitas dan morbiditas di masyarakat. Selain merupakan the silent killer, prevalensi penyakit ini meningkat diseluruh dunia. Prevalensi hipertensi di Indonesia tahun 2013 sebesar $25,8 \%$ dan meningkat menjadi 34,1\% ditahun 2018. Penelitian ini bertujuan untuk mengetahui karakteristik pasien hipertensi, mengetahui hubungan antara karakteristik sosiodemografi dengan tingkat pengetahuan pasien hipertensi dan mengetahui hubungan antara tingkat pengetahuan pasien hipertensi dengan clinical outcomenya. Merupakan penelitian deskriptif kuantitatif menggunakan rancangan cross sectional yang dilakukan terhadap pasien hipertensi di poli penyakit dalam RSUP DR. M. Djamil Padang pada bulan Februari hingga April 2019. Teknik pengambilan sampel adalah purposive sampling dan penentuan tingkat pengetahuan responden diketahui dari perolehan skor melalui wawancara menggunakan kuesioner yang divalidasi. Analisa data menggunakan statistika chi square. Diperoleh hasil 114 responden dengan karakteristik 50\% pasien laki laki dan 50\% pasien perempuan, kelompok umur terbanyak rentang umur 46-55 tahun (31,6\%), Pendidikan terbanyak SMA (46,5\%), pekerjaan terbanyak wiraswasta (33,3\%). Tidak terdapat hubungan yang signifikan antara jenis kelamin dan umur pasien hipertensi dengan tingkat pengetahuannya dan terdapat hubungan yang signifikan antara pendidikan dan jenis pekerjaan pasien hipertensi dengan tingkat pengetahuannya. Dari penelitian ini disimpulkan bahwa adanya hubungan yang signifikan antara tingkat pengetahuan pasien hipertensi dengan clinical outcomenya.

Kata kunci: pengetahuan; hipertensi; clinical outcome; RSUP DR. M. Djamil.

\section{Pendahuluan}

Hipertensi atau yang dikenal dengan sebutan tekanan darah tinggi adalah suatu keadaan dimana tekanan darah seseorang mencapai lebih dari 140/90 mmHg. Penyakit ini dikenal sebagai the silent killer karena sering dijumpai tanpa gejala dan penderita tidak mengetahui dirinya mengidap hipertensi sebelum memeriksakan tekanan darahnya. Jika tidak diobati dan ditangani akan menimbulkan komplikasi yang dapat mengakibatkan cacat maupun kematian [1]. Hipertensi merupakan masalah kesehatan masyarakat yang umum di negara berkembang. Hipertensi yang tidak segera ditangani berdampak pada munculnya penyakit degeneratif, seperti gagal jantung (congestif heart failure), gagal ginjal (end stage renal disease), dan penyakit pembuluh

\section{Article history}

Received: 31 Mei 2019 Accepted: 05 Agust 2019 Published: 20 Agust 2019

Access this article

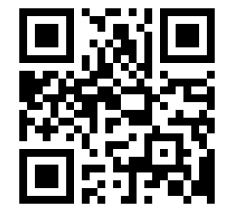


darah perifer [2].

WHO mencatat pada tahun 2013 terjadi sejumlah 839 juta kasus hipertensi dan diperkirakan menjadi 1,15 milyar pada tahun 2025 atau sekitar 29\% dari total penduduk dunia, dimana penderitanya lebih banyak pada wanita dibanding pria. Kenaikan kasus hipertensi terjadi terutama di negara-negara berkembang [3]. Prevalensi hipertensi di Indonesia pada usia 18 tahun keatas mengalami kenaikan dari $25,8 \%$ menjadi $34,1 \%$. Kenaikan prevalensi penyakit ini berkaitan dengan kenaikan prevalensi kebiasaan merokok dari $7,2 \%$ menjadi $9,1 \%$, konsumsi alkohol dari $3 \%$ menjadi 3,3\% dan rendahnya aktifitas fisik dari $26,1 \%$ menjadi 33,5\%.

Banyak faktor yang berperan dalam terjadinya hipertensi meliputi faktor risiko yang tidak dapat dikendalikan atau diubah (mayor) seperti umur, jenis kelamin, ras dan keturunan dan faktor risiko yang dapat dikendalikan atau diubah (minor) seperti obesitas, stress, merokok, aktivitas fisik, konsumsi minuman beralkohol yang berlebihan, konsumsi garam yang tinggi dan kurang serat [4]. Berkaitan dengan faktor gaya hidup maka pengetahuan menjadi faktor utama agar penyakit hipertensi ini tidak berkembang menjadi komplikasi yang lebih parah. Seseorang yang mempunyai pengetahuan tentang penyakit dan berbagai penyebabnya maka akan melakukan tindakan sebaik mungkin agar penyakitnya tidak berlanjut [5].

Pengetahuan atau ranah kognitif merupakan domain yang sangat penting dalam membentuk tindakan seseorang (overt behavior). Perilaku yang didasari dengan pengetahuan akan lebih langgeng dibandingkan perilaku yang tidak didasarkan pada pengetahuan. Pengetahuan inilah yang dapat mempengaruhi pasien hipertensi dalam melakukan upaya pengendalian tekanan darah [6]. Strategi untuk mengontrol hipertensi merupakan bagian terpenting dari beberapa upaya pengendalian tekanan darah dalam mencegah komplikasi penyakit [7]. Penderita hipertensi memerlukan kepatuhan yang berkelanjutan pada terapi farmakologi agar tercapai dan terpeliharanya tekanan darah dan menurunkan resiko penyakit kardiovaskular serta kematian [8].

Hasil penelitian yang dilakukan oleh Dirhan tentang hubungan pengetahuan pasien hipertensi dengan derajat sistole dan diastole pasien diperoleh hasil $\mathrm{p}$ value $=0,000$ yang berarti terdapat hubungan yang bermakna antara tingkat pengetahuan pasien hipertensi dengan tekanan darahnya. Ini artinya semakin baik pengetahuan pasien hipertensi tentang penyakit yang dideritanya maka tekanan darah dapat ditekan kearah normal [9]. Oleh karena itu, penelitian ini dilakukan untuk melihat hubungan antara tingkat pengetahuan pasien hipertensi dengan clinical outcomenya di poli penyakit dalam RSUP DR. M. Djamil Padang.

\section{Metode Penelitian}

Jenis Penelitian

Penelitian ini merupakan penelitian deskriptif kuantitatif menggunakan rancangan cross-sectional. Data prospektif diperoleh dari hasil wawancara menggunakan kuesioner terhadap pasien hipertensi rawat jalan di poli penyakit dalam RSUP DR. M. Djamil Padang.

Penetapan Sampel

Teknik sampling yang digunakan dalam penelitian ini adalah purposive sampling dimana peneliti menentukan pengambilan sampel dengan cara menetapkan ciri-ciri khusus yang sesuai dengan tujuan penelitian. Kriteria inklusi adalah pasien hipertensi yang berumur 18 tahun ke atas yang bersedia menjadi responden. Kriteria eksklusi adalah pasien hipertensi berumur dibawah 18 tahun, tidak bersedia menjadi responden dan memiliki gangguan dalam berkomunikasi.

Pengumpulan Data

Data berupa skor pengetahuan diperoleh langsung dari responden melalui wawancara menggunakan kuesioner yang divalidasi terlebih dahulu. Kuesioner terdiri dari 10 pertanyaan yaitu: Hipertensi disebut juga sebagai penyakit apa?, apakah penyakit hipertensi merupakan penyakit keturunan?, apa contoh makanan yang dapat menyebabkan hipertensi?, apa contoh kegiatan yang dapat mengurangi risiko hipertensi?, penyakit hipertensi banyak terjadi pada umur berapa?, apa saja gejala yang ditimbulkan oleh penyakit hipertensi?, berapa tekanan darah tinggi?, apakah dengan bertambah umur tekanan darah juga semakin bertambah?, apakah kelebihan berat badan (obesitas) dapat menyebabkan hipertensi?, bagaimana cara penanggulangan penyakit hipertensi?. Wawancara dilakukan terhadap pasien hipertensi rawat jalan di poli penyakit dalam RSUP DR. M. Djamil Padang pada periode Februari hingga April 2019. Data yang dikumpulkan berupa nama, beberapa faktor sosiodemografi (jenis kelamin, umur, pendidikan, pekerjaan), tingkat pengetahuan pasien hipertensi tentang penyakitnya dan tekanan darah pasien.

Tingkat pengetahuan pasien hipertensi diukur melalui pertanyaan yang meliputi kemampuan responden dalam mengetahui penyakit hipertensi, memahami komplikasi hipertensi, faktor risiko, penyebab, gejala hipertensi, penanganan dan penanggulangan hipertensi serta pemenuhan diit hipertensi. Jika mampu menjawab pertanyaan dengan benar, diberi nilai 1 dan jika jawaban salah, diberi nilai 0 . Pengukuran aspek pengetahuan pasien 
diklasifikasikan menjadi 3 kategori yaitu: pengetahuan kategori kurang jika responden memperoleh skor $\leq 55 \%$, pengetahuan kategori cukup jika responden memperoleh skor $56 \%$ - 74\% dan pengetahuan kategori baik jika responden memperoleh skor $\geq 75 \%$. Clinical outcome adalah tekanan darah pasien hipertensi yang diukur menggunakan alat tensimeter. Tekanan darah diklasifikasikan menjadi 2 kategori yaitu: target tekanan darah tercapai jika tekanan darah kecil dari 140/90 $\mathrm{mmHg}$ dan target tekanan darah tidak tercapai jika tekanan darah besar dari 140/90 mmHg.

\section{Analisa Data}

Data yang sudah terkumpul kemudian dianalisis menggunakan program SPSS (Statistical Package for the Social Sciences) menggunakan uji chi square dengan tingkat kepercayaan 5\% untuk melihat hubungan antara faktor sosiodemografi (jenis kelamin, umur, pendidikan, pekerjaan) dengan tingkat pengetahuan pasien hipertensi dan untuk melihat hubungan antara tingkat pengetahuan pasien hipertensi dengan clinical outcomenya.

\section{Hasil dan Diskusi}

Dari penelitian yang telah dilakukan, diperoleh sampel sebanyak 114 pasien yang memenuhi kriteria inklusi. Distribusi frekuensi karakteristik sosiodemografi responden periode Februari hingga April 2019 dapat dilihat pada tabel 1.

Sebagaimana yang ditunjukkan oleh tabel 1 diperoleh responden laki-laki sebanyak 57 orang (50\%) dan perempuan sebanyak 57 orang (50\%). Diperoleh jumlah imbang antara pasien laki-laki dengan pasien perempuan sebab peluang kejadian hipertensi antara lakilaki dengan perempuan sama saja. Cortas mengatakan prevalensi terjadinya hipertensi pada pria sama dengan wanita namun, hormon estrogen melindungi wanita dari penyakit kardiovaskuler sebelum menopause [10]. Saat fase menopause, terjadi penurunan hormon estrogen yang berpengaruh terhadap peningkatan tekanan darah dan penurunan hormon estrogen mengakibatkan gangguan metabolisme lemak yang ditandai dengan meningkatnya LDL kolesterol dan rendahnya HDL. Hal ini memicu terjadinya aterosklerosis yang merupakan faktor risiko hipertensi [11]. Namun hasil penelitian ini berbeda dengan penelitian Amaliah dengan hasil pasien hipertensi laki-laki 41,6\% dan pasien hipertensi perempuan 58,4\% [12] dan penelitian Muslimin dengan hasil pasien hipertensi lakilaki 37,7\% dan pasien hipertensi perempuan 62,3\% [13].

Pasien hipertensi terbanyak berada pada rentang umur 46-55 tahun. Hal ini sejalan dengan penelitian Tjekyan dengan umur pasien hipertensi terbanyak berada diatas 40 tahun [14]. Sesuai dengan teori, bahwa tekanan darah umumnya mengalami peningkatan dimulai setelah usia 40 tahun dikarenakan arteri akan mengalami penebalan sehingga pembuluh darah akan menyempit dan diikuti oleh penurunan elastisitas pembuluh darah sehingga pembuluh darah menjadi kaku. Pembuluh darah tidak dapat menjalankan fungsinya dengan baik untuk mengembang pada saat jantung memompa darah sehingga jantung harus meningkatkan denyutnya pada pembuluh darah yang menyempit agar aliran darah dapat didistribusikan keseluruh tubuh. Hal ini menyebabkan naiknya tekanan darah [15].

Karakteristik pendidikan terbanyak adalah tingkat SMA sebanyak 53 orang (46,5\%) dikarenakan pasien hipertensi yang berobat ke poli penyakit dalam RSUP DR. M. Djamil Padang didominasi oleh pasien berpendidikan terakhir SMA. Hasil ini sejalan dengan penelitian oleh Tarigan yang menunjukkan sebanyak $48,1 \%$ pasien hipertensi dengan pendidikan terakhir SMA [16] dan penelitian sinuraya menunjukkan sebanyak 34\% pasien hipertensi dengan pendidikan terakhir SMA [17].

Karakteristik pekerjaan terbanyak pada penelitian ini adalah wiraswasta sebanyak 38 orang (33,3\%). Hal ini menunjukkan kalau kejadian hipertensi lebih banyak terjadi pada orang yang bekerja. Sesuai dengan hasil penelitian Azhari menunjukan bahwa dari 60 responden yang bekerja, yang menderita hipertensi sebanyak 44 orang $(73,3 \%)$. Dan dari 52 responden yang tidak bekerja, yang menderita hipertensi sebanyak 24 orang (46,2\%). Hasil analisa chi-square didapatkan $\mathrm{p}$ value $=0,006<\alpha(0,05)$, berarti ada hubungan antara pekerjaan dengan kejadian hipertensi dan nilai Odds Ratio $(\mathrm{OR})=3,208$, yang berarti, responden yang bekerja mempunyai peluang sebanyak 3,2 kali untuk terkena penyakit hipertensi dibandingkan dengan responden yang tidak bekerja [18].

Tabel 2 menjelaskan tentang hubungan karakteristik sosiodemografi (Jenis kelamin, umur, tingkat pendidikan, jenis pekerjaan) dengan tingkat pengetahuan. Diketahui dari 100\% pasien laki-laki, 79\% berpengetahuan baik, 19,3\% berpengetahuan cukup, $1,7 \%$ berpengetahuan kurang. Dari $100 \%$ pasien perempuan, $82,5 \%$ berpengetahuan baik, 14\% berpengetahuan cukup, 3,5\% berpengetahuan kurang. Berdasarkan uji chi square antara jenis kelamin dengan pengetahuan diperoleh nilai $\mathrm{p}>0,05$ yaitu 0,795 artinya tidak terdapat hubungan yang signifikan antara jenis kelamin dengan pengetahuan pasien. Artinya dengan perbedaan gender antara laki-laki dan perempuan tidak akan mempengaruhi tingkat pengetahuan pasien 
hipertensi.

Dari tabel 2 diketahui $100 \%$ pasien umur 17-35 tahun berpengetahuan baik, 90,5\% pasien umur 36-45 tahun berpengetahuan baik, 77,8\% pasien umur 46-55 tahun berpengetahuan baik, 69\% pasien umur 56-65 tahun berpengetahuan baik, 72,7\% pasien umur >65 tahun berpengetahuan baik. Berdasarkan uji chi square antara umur dengan pengetahuan diperoleh nilai $\mathrm{p}>0,05$ yaitu 0,553 artinya tidak terdapat hubungan yang signifikan antara umur dengan pengetahuan pasien. Ini berarti dengan bertambahnya umur seseorang belum tentu menambah pengetahuannya tentang penyakit hipertensi. Penelitian ini sejalan dengan hasil penelitian Novitaningtyas yang menyatakan tidak ada hubungan antara umur pasien hipertensi dengan pengetahuannya mengenai penyakit hipertensi [19].

Dari tabel 2 diketahui $100 \%$ pasien tidak sekolah berpengetahuan baik, $72 \%$ pasien tamat
SD berpengetahuan baik, $69,2 \%$ pasien tamat SMP berpengetahuan baik, $86,8 \%$ pasien tamat SMA berpengetahuan baik, dan $81 \%$ pasien tamat perguruan tinggi berpengetahuan baik. Berdasarkan uji chi square antara pendidikan dengan pengetahuan diperoleh nilai $\mathrm{p}$ $<0,05$ yaitu 0,013 artinya ada hubungan yang signifikan antara pendidikan dengan pengetahuan pasien. Penelitian ini sejalan dengan penelitian yang dilakukan oleh Wahyuni dan Eksanoto serta Sadeq yang membuktikan bahwa terdapat hubungan yang signifikan antara tingkat pendidikan dengan pengetahuan pasien hipertensi [20,21]. Pendidikan yang rendah akan menghambat perkembangan sikap seseorang terhadap nilai -nilai atau informasi yang baru diperkenalkan, sebaliknya makin tinggi tingkat pendidikan seseorang, semakin mudah menerima informasi sehingga semakin banyak pula pengetahuan yang dimilikinya [22]. Pada penelitian ini diperoleh hasil semakin tinggi tingkat pendidikan seseorang, semakin baik

Tabel 1. Distribusi Frekuensi Karakteristik Sosiodemografi Responden

\begin{tabular}{|c|c|c|c|c|}
\hline No & Karakteristik Sosiodemografi & Kelompok & Frekuensi & Persentase \\
\hline \multirow[t]{3}{*}{1} & Jenis kelamin & Laki-laki & 57 & 50,0 \\
\hline & & Perempuan & 57 & 50,0 \\
\hline & & Jumlah & 114 & 100 \\
\hline \multirow[t]{7}{*}{2} & Umur & $17-25$ tahun & 7 & 6,1 \\
\hline & & $26-35$ tahun & 10 & 8,8 \\
\hline & & $36-45$ tahun & 21 & 18,4 \\
\hline & & $46-55$ tahun & 36 & 31,6 \\
\hline & & $56-65$ tahun & 29 & 25,4 \\
\hline & & $>65$ & 11 & 9,7 \\
\hline & & Jumlah & 114 & 100 \\
\hline \multirow[t]{6}{*}{3} & Pendidikan & Tidak sekolah & 2 & 1,8 \\
\hline & & SD & 25 & 21,9 \\
\hline & & SMP & 13 & 11,4 \\
\hline & & SMA & 53 & 46,5 \\
\hline & & Perguruan tinggi & 21 & 18,4 \\
\hline & & Jumlah & 114 & 100 \\
\hline \multirow[t]{6}{*}{4} & Pekerjaan & Tidak bekerja & 20 & 17,5 \\
\hline & & PNS & 10 & 8,8 \\
\hline & & Wiraswasta & 38 & 33,3 \\
\hline & & IRT & 36 & 31,6 \\
\hline & & Lain-lain & 10 & 8,8 \\
\hline & & Jumlah & 114 & 100 \\
\hline
\end{tabular}


pula tingkat pengetahuannya. Sejalan dengan penelitian Sinuraya yang memperlihatkan hasil bahwa pasien dengan pengetahuan kategori sedang dan kurang umumnya adalah pasien hipertensi dengan tingkat pendidikan yang rendah dan pasien dengan pengetahuan kategori baik umumnya adalah pasien hipertensi dengan pendidikan tinggi [17].

Dari tabel 2 diketahui $75 \%$ pasien tidak bekerja berpengetahuan baik, 90\% pasien PNS berpengetahuan baik, $84,2 \%$ pasien wiraswasta berpengetahuan baik, $80,6 \%$ ibu rumah tangga berpengetahuan baik dan $70 \%$ pasien dengan pekerjaan lain-lain berpengetahuan baik. Berdasarkan uji chi square antara pekerjaan dengan pengetahuan diperoleh nilai $\mathrm{p}<0,05$ yaitu 0,031 artinya ada hubungan yang signifikan antara jenis pekerjaan dengan pengetahuan pasien. Pada penelitian ini terlihat pengetahuan kategori baik tertinggi berada pada pasien hipertensi yang bekerja sebagai PNS, disusul oleh pasien yang bekerja sebagai wiraswasta. Hal ini menunjukkan bahwa lingkungan pekerjaan dapat menjadikan seseorang memperoleh pengalaman dan pengetahuan baik secara langsung maupun tidak langsung. Jenis pekerjaan yang sering berinteraksi dengan orang lain dapat menambah pengetahuan bila dibandingkan dengan pekerjaan tanpa interaksi dengan orang lain. Pengalaman belajar dalam bekerja akan memberikan pengetahuan dan keterampilan profesional serta pengalaman belajar dalam bekerja akan dapat mengembangkan kemampuan dalam mengambil keputusan yang merupakan keterpaduan menalar secara ilmiah dan etik [23].

Hubungan antara pengetahuan pasien hipertensi dengan clinical outcome dapat dilihat pada tabel 3. 100\% Pasien dengan pengetahuan kurang, clinical outcome tidak

Tabel 2. Hubungan Karakteristik Sosiodemografi dengan Tingkat Pengetahuan

\begin{tabular}{|c|c|c|c|c|c|c|c|c|c|c|}
\hline \multicolumn{11}{|c|}{ Pengetahuan } \\
\hline \multirow{2}{*}{ No } & \multirow{2}{*}{ Karakteristik Sosiodemografi } & \multicolumn{2}{|c|}{ Kurang } & \multicolumn{2}{|c|}{ Cukup } & \multicolumn{2}{|c|}{ Baik } & \multicolumn{2}{|c|}{ Total } & \multirow[t]{2}{*}{$P$ value } \\
\hline & & $f$ & $\%$ & $\mathbf{f}$ & $\%$ & f & $\%$ & f & $\%$ & \\
\hline \multirow[t]{3}{*}{1} & Jenis Kelamin & & & & & & & & & \\
\hline & Laki-laki & 1 & 1,7 & 11 & 19,3 & 45 & 79,0 & 57 & 100 & 0,795 \\
\hline & Perempuan & 2 & 3,5 & 8 & 14,0 & 47 & 82,5 & 57 & 100 & \\
\hline \multirow[t]{7}{*}{2} & Umur & & & & & & & & & \\
\hline & $17-25$ tahun & 0 & 0 & 0 & 0 & 7 & 100 & 7 & 100 & \\
\hline & $26-35$ tahun & 0 & 0 & 0 & 0 & 10 & 100 & 10 & 100 & \\
\hline & $36-45$ tahun & 0 & 0 & 2 & 9,5 & 19 & 90,5 & 21 & 100 & 0,553 \\
\hline & $46-55$ tahun & 0 & 0 & 8 & 22,2 & 28 & 77,8 & 36 & 100 & \\
\hline & $56-65$ tahun & 3 & 10,3 & 6 & 20,7 & 20 & 69,0 & 29 & 100 & \\
\hline & $>65$ & 0 & 0 & 3 & 27,3 & 8 & 72,7 & 11 & 100 & \\
\hline \multirow[t]{6}{*}{3} & Pendidikan & & & & & & & & & \\
\hline & Tidak sekolah & 0 & 0 & 0 & 0 & 2 & 100 & 2 & 100 & \\
\hline & SD & 0 & 0 & 7 & 28,0 & 18 & 72,0 & 25 & 100 & \\
\hline & SMP & 1 & 7,7 & 3 & 23,1 & 9 & 69,2 & 13 & 100 & 0,013 \\
\hline & SMA & 2 & 3,8 & 5 & 9,4 & 46 & 86,8 & 53 & 100 & \\
\hline & Perguruan tinggi & 0 & 0 & 4 & 19,0 & 17 & 81,0 & 21 & 100 & \\
\hline \multirow[t]{6}{*}{4} & Pekerjaan & & & & & & & & & \\
\hline & Tidak bekerja & 2 & 10,0 & 3 & 15,0 & 15 & 75,0 & 20 & 100 & \\
\hline & PNS & 0 & 0 & 1 & 10,0 & 9 & 90,0 & 10 & 100 & 0,031 \\
\hline & Wiraswasta & 1 & 2,6 & 5 & 13,2 & 32 & 84,2 & 38 & 100 & \\
\hline & IRT & 0 & 0 & 7 & 19,4 & 29 & 80,6 & 36 & 100 & \\
\hline & Lain-lain & 0 & 0 & 3 & 30,0 & 7 & 70,0 & 10 & 100 & \\
\hline
\end{tabular}


tercapai. Dari 100\% pasien pengetahuan cukup, 68,4\% clinical outcome tidak tercapai dan 31,6\% clinical outcome tercapai. Dari 100\% pasien pengetahuan baik, 55,4\% clinical outcome tidak tercapai dan 44,6\% clinical outcome tercapai. Berdasarkan uji chi square antara pengetahuan dengan clinical outcome diperoleh nilai $p<0,05(\mathrm{p}=0,019)$, yang artinya terdapat hubungan yang signifikan antara pengetahuan pasien hipertensi dengan clinical outcomenya. Hasil ini sejalan dengan hasil penelitian Rahayu dan Anowie yang memperlihatkan terdapat hubungan yang signifikan antara pengetahuan pasien hipertensi dengan tekanan darahnya [24,25]

Artinya, responden dengan tingkat pengetahuan yang baik tentang hipertensi umumnya tekanan darahnya terkendali, sedangkan responden yang mempunyai tingkat pengetahuan tidak baik mengenai hipertensi umumnya tekanan darahnya tidak terkendali. Karena pengetahuan dan kesadaran pasien hipertensi tentang penyakitnya merupakan faktor penting dalam mencapai kontrol tekanan darah dan pengetahuan individu mengenai hipertensi membantu dalam pengendalian hipertensi. Sebab dengan pengetahuan ini individu akan patuh pada pengobatan yang dijalaninya dan berusaha mencegah hipertensi dengan cara mengubah pola makan, olahraga rutin, jaga berat badan ideal, menjauhi minum alkohol, kelola stres dengan baik dan cek tekanan darah secara berkala. Sesuai dengan pendapat Maryono bahwa pengetahuan yang baik akan mampu merubah gaya hidup dengan cara berhenti merokok sedini mungkin, berolahraga secara teratur, perbaikan diet, hindari stres serta hindari pola hidup tidak sehat [26].

Hasil penelitian ini sejalan dengan penelitian Dirhan yang menyatakan bahwa terdapat hubungan yang bermakna antara pengetahuan pasien hipertensi dengan derajat sistole dan diastole pasien dengan perolehan niai $\mathrm{P}=0,000$ [9]. Hal ini sesuai dengan pendapat Green bahwa tingkat kesehatan seseorang dapat ditentukan oleh tingkat pengetahuan dari orang tersebut, sehingga semakin baik tingkat pengetahuan seseorang maka tingkat kesehatan orang tersebut juga akan semakin baik [5].

Tabel 3. Hubungan Pengetahuan dengan Clinical Outcome Responden

\begin{tabular}{|c|c|c|c|c|c|c|c|c|}
\hline \multirow{3}{*}{ No } & \multirow{3}{*}{ Pengetahuan } & \multicolumn{6}{|c|}{ Clinical Outcome } & \multirow{3}{*}{$P$ value } \\
\hline & & \multicolumn{2}{|c|}{ Tercapai } & \multicolumn{2}{|c|}{ Tidak Tercapai } & \multicolumn{2}{|c|}{ Total } & \\
\hline & & f & $\%$ & f & $\%$ & $f$ & $\%$ & \\
\hline 1 & Kurang & 0 & 0 & 3 & 100 & 3 & 100 & \\
\hline 2 & Cukup & 6 & 31,6 & 13 & 68,4 & 19 & 100 & 0,019 \\
\hline 3 & Baik & 41 & 44,6 & 51 & 55,4 & 92 & 100 & \\
\hline
\end{tabular}

\section{Kesimpulan}

Dari penelitian yang telah dilakukan dapat disimpulkan distribusi karakteristik pasien hipertensi laki-laki sebanyak 57 orang $(50 \%)$ dan pasien hipertensi perempuan sebanyak 57 orang $(50 \%)$ dengan distribusi frekuensi terbanyak berada pada rentang umur 46-55 tahun sebanyak 36 orang (31,6\%), pendidikan SMA sebanyak 53 orang (46,5\%), jenis pekerjaan terbanyak wiraswasta sebanyak 38 orang $(33,3 \%)$. Tidak terdapat hubungan yang signifikan antara jenis kelamin dan umur dengan tingkat pengetahuan pasien hipertensi $(p>0,05)$ dan terdapat hubungan yang signifikan antara tingkat pendidikan dan jenis pekerjaan dengan tingkat pengetahuan pasien hipertensi $(p<0,05)$. Serta terdapat hubungan yang signifikan antara tingkat pengetahuan pasien hipertensi dengan clinical outcomenya $(\mathrm{p}<0,05)$.

\section{Referensi}

[1] Bustan MN. Epidemiologi penyakit tidak menular. cetakan 2. Jakarta: Rineka Cipta; 2007.

[2] Koelling TM, Johnson ML, Cody RJ. Discharge education improves clinical outcome in patients with chronic heart failure. US national library of medicines. J PubMed. 2005;111(2):85-179.

[3] Triyanto, Endang. Pelayanan keperawatan bagi penderita hipertensi secara terpadu. Yogyakarta: Graha Ilmu; 2014.

[4] Palmer A, William, B. Tekanan darah tinggi. Jakarta: Erlangga; 2007.

[5] Notoatmodjo S. Promosi kesehatan dan ilmu perilaku. Jakarta: Rineka Cipta; 2007.

[6] Notoatmodjo S. Pengantar pendidikan kesehatan dan ilmu perilaku edisi 1. Yogyakarta: Andi Offset; 2012.

[7] Yancy CW, Jessup M, Bazkurt B, Butler J, Casey DE, Drazner MH. ACCF/AHA Guideline for the management of heart failure: A report of the american collage of cardiology foundation/american heart association task force on practice guidelines. American J College Of Cardiology. 2013;62(16):539-1495. 
[8] Krousel-Wood M, Joyce C, Holt EW, Muntner P, Webber LS, Morisky $D E$. Predictors of decline in medication adherence: Results from cohort study of medication adherence among older adults. US national library of medicines. American J PubMed. 2011;58(5):10804.

[9] Dirhan. Hubungan pengetahuan, sikap dan ketaatan berobat dengan derajat sistole dan diastole pasien hipertensi di puskesmas sukamerindu kota bengkulu. J IImiah Farmasi. 2012;9(1):1-10

[10] Cortas K. Hypertension [Internet]. Medscape. 2018 [cited 27 November 2018]. Available from: http:// wemedicine.medscape. com/article/241381

[11] Proverawati A. Menopause dan sindrome pre-menopause. Yogyakarta: Nuha Medika; 2010.

[12] Amaliah F, Sudikno. Faktor risiko hipertensi pada orang umur 45-74 tahun di pulau sulawesi. J Gizi Indon. 2014;37(2):124-151.

[13] Muslimin I, Adiningsih R. Analisis faktor kejadian hipertensi di wilayah kerja puskesmas binanga kabupaten mamuju. J Kesehatan Suara Forikes. 2017;8(3):161-165.

[14] Tjekyan S. Angka kejadian dan faktor risiko hipertensi di kota palembang. J Mks. 2014;46(1):1-11.

[15] Yogiantoro M. 2010. Hipertensi essensial: Buku ajar ilmu penyakit dalam. FKUI. Jakarta: Interna Publishing; 2010

[16] Taringan AR, Lubis Z. Pengaruh pengetahuan, sikap dan dukungan keluarga terhadap diet hipertensi di desa hulu kecamatan pancur batu medan. J Kesehatan. 2018;11(1):9-17.

[17] Sinuraya RK, Siagian BJ, Taufik A. Pengukuran tingkat pengetahuan tentang hipertensi pada pasien hipertensi di kota bandung. J Farmasi Klinik Indonesia. 2017;6(4):290-297.
[18] Azhari MH. Faktor-faktor yang berhubungan dengan kejadian hipertensi di puskesmas makrayu kecamatan ilir barat II palembang. J Ilmu Kesehatan. 2017;2(1):23-30.

[19] Novitaningtyas T. Hubungan Karakteristik (umur,jenis kelamin,tingkat pendidikan) dan Aktivitas Fisik dengan Tekanan Darah Pada Lansia di Kelurahan Makamhaji Kecamatan Kartasura Kabupaten Sukoharjo [skripsi].Surakarta: Fakultas IImu Kesehatan Universitas Muhammadiyah; 2014.

[20] Wahyuni, Eksanoto D. Hubungan tingkat pendidikan dan jenis kelamin dengan kejadian hipertensi di kelurahan jagalan di wilayah kerja puskesmas pucang sawit surakarta. J Ilmu Keperawatan Indonesia. 2013;1(1):79-85.

[21] Sadeq R, Lafta K. Knowledge, attitude and practice about hypertension in hypertensive patients attending hospitals in baghdad, iraq. South Easth Asian J Public Health. 2017;7(1):29-34.

[22] Notoatmodjo, S. Pendidikan dan perilaku kesehatan. Jakarta: Rineka Cipta; 2003.

[23] Nursalam. Dokumentasi keperawatan. Jakarta: EGC; 2001.

[24] Rahayu LL. Hubungan Antara Pengetahuan Masyarakat tentang Penyakit Hipertensi dengan Pengaturan Pola Diet Hipertensi di Puskesmas Nguter Nguter Surakarta. [skripsi]. Surakarta: Stikes Muhammadiyah; 2012.

[25] Anowie F, Darkwa S. The knowledge, attitude and lifestyle practices of hypertensive patients in the cape coast metropolis ghana. J of Scientific Research \& Reports. 2015;8(7):1-15.

[26] Maryono D. Penyakit jantung. Jakarta: PT Bhuana Ilmu Populer; 2007.

Copyright $\odot 2019$ The author(s). You are free to share (copy and redistribute the material in any medium or format) and adapt (remix, transform, and build upon the material for any purpose, even commercially) under the following terms: Attribution - You must give appropriate credit, provide a link to the license, and indicate if changes were made. You may do so in any reasonable manner, but not in any way that suggests the licensor endorses you or your use; ShareAlike - If you remix,
transform, or build upon the material, you must distribute your contributions under the same license as the original (https://creativecommons.org/licenses/by-sa/4.0/) 